\title{
CORRESPONDENCE SECTION
}

\section{Fatty acid composition of human milk lipids in Chilean women}

Sir,

The fatty acid composition of human milk is different according to publications of several countries. We made a prospective and observational study, and we analysed a group of mothers who delivered at the Hospital Sótero del Río maternity ward in Santiago, Chile. Eleven delivered full-term infants and nine preterm infants with gestational ages between 31 and $34 \mathrm{wk}$. We obtained human milk samples under standardized conditions in order to characterize the fatty acid composition of colostrum and transitional milk in Chilean women during the first month of life. Food consumption was evaluated based on two 24-h dietary recalls and a habitual dietary intake questionnaire. Macronutrient and fat intake was derived using local food composition tables $(1,2)$. All mothers signed consent forms which had been approved by the Hospital Ethics Committee that regulates human research.

Two samples were obtained from each mother: the first one between the second and third postnatal days, and the second between 15 and $18 \mathrm{~d}$. Five-millilitre samples were extracted manually by the mothers during the morning, 3 min after the infant initiated lactating from the corresponding breast $(3,4)$. Human milk was collected in a glass test tube and frozen at $-70^{\circ} \mathrm{C}$ until processed.

Samples were processed using the one-step extraction direct trans-esterification method of Lepage and Roy (5). Fatty acid analysis methodology has been published by Bligh and Dyer (6). Results are expressed as relative content $\mathrm{mg} / 100 \mathrm{mg}$ of total fatty acids. (7).
Mothers participating in the study $(n=20)$ were a population of the south-east of Santiago, beneficiary of the National Health Service and predominantly of low socio-economic status. They consumed an omnivorous diet, with a mean energy intake of $2270 \mathrm{kcal}$ per day: $20 \%$ energy derived from fat, $68 \%$ from carbohydrates and $12 \%$ from protein. The proportion of saturates, monounsaturated and polyunsaturated lipids was similar. Concerning total polyunsaturated fatty acids (PUFA), the $n-6$ was estimated in $88 \%$ and the $n-3$ in $12 \%$. The relation PUFA $n-6 / P U F A ~ n-3$ was $7.5: 1$ (Table 1).

The docosahexaenoic acid (DHA) and eicosapentaenoic acid (EPA) content is higher than that reported in industrialized Western countries with a typical timerelated decline with advancing lactation $(8-10)$. The content of saturated and monounsaturated fatty acids was similar to those reported in industrialized Western countries, while the DHA and EPA were more in line with Asian diets. We noted that dietary fat consumed was rich in omega-3 sources; this included rapeseed oil used for cooking and by-products such as eggs, poultry and porcine meats which are fed with fish meals (11).

Conclusion: Fatty acid composition of human milk lipids from Chilean mothers revealed a significant effect of the local diet. The fatty acid pattern observed demonstrated a high relative content of docosahexaenoic acid. This is different from what has been observed in other countries.

Table 1. Fatty acid composition of human milk from mothers giving birth to preterm and term infants according to days of lactation ( $\mathrm{g} / 100 \mathrm{~g}$ ).

\begin{tabular}{|c|c|c|c|c|}
\hline & Term infants $2-3 \mathrm{~d}$ & Term infants $15-18 \mathrm{~d}$ & Preterm 2-3 d & Preterm $15-18 \mathrm{~d}$ \\
\hline Total saturates & $38.9 \pm 2.1$ & $40.9 \pm 3.2$ & $40.4 \pm 3.0$ & $43.7 \pm 4.3$ \\
\hline $\begin{array}{l}\text { Monounsaturate } \\
\text { n-6 PUFA }\end{array}$ & $36.6 \pm 3.0$ & $36.8 \pm 3.8$ & $35.4 \pm 2.2$ & $34.4 \pm 3.5$ \\
\hline $18: 2$ & $17.67 \pm 2.70$ & $17.32 \pm 2.62$ & $16.74 \pm 1.44$ & $17.22 \pm 2.89$ \\
\hline $18: 3$ & $0.09 \pm 0.02$ & $0.14 \pm 0.08^{*}$ & $0.05 \pm 0.03$ & $0.12 \pm 0.06$ \\
\hline $20: 2$ & $1.42 \pm 0.35 \#$ & $0.66 \pm 0.13$ & $1.59 \pm 0.28 \#$ & $0.66 \pm 0.13$ \\
\hline $20: 3$ & $0.93 \pm 0.32 \#$ & $0.54 \pm 0.14$ & $1.06 \pm 0.19 \#$ & $0.55 \pm 0.24$ \\
\hline $20: 4$ & $1.25 \pm 0.55 \#$ & $0.63 \pm 0.12$ & $1.16 \pm 0.30 \#$ & $0.57 \pm 0.16$ \\
\hline $22: 4$ & $0.42 \pm 0.22 \#$ & $0.12 \pm 0.06$ & $0.53 \pm 0.12 \#$ & $0.09 \pm 0.03$ \\
\hline Total n-6 PUFA & $21.8 \pm 2.7$ & $19.4 \pm 2.6$ & $21.1 \pm 1.4$ & $19.2 \pm 3.1$ \\
\hline Total n-6 LCP & $4.0 \pm 1.3$ & $2.0 \pm 0.3$ & $4.3 \pm 0.5$ & $1.9 \pm 0.4$ \\
\hline \multicolumn{5}{|l|}{ n-3 PUFA } \\
\hline $18: 3$ & $1.04 \pm 0.26$ & $1.46 \pm 0.52^{*}$ & $0.97 \pm 0.17$ & $1.60 \pm 0.93^{*}$ \\
\hline $20: 5$ & $0.24 \pm 0.08$ & $0.39 \pm 0.19$ & $0.22 \pm 0.07$ & $0.21 \pm 0.13$ \\
\hline $22: 5$ & $0.61 \pm 0.24 \#$ & $0.34 \pm 0.08$ & $0.84 \pm 0.18 \#$ & $0.30 \pm 0.10$ \\
\hline $22: 6$ & $0.89 \pm 0.33$ & $0.69 \pm 0.15$ & $1.08 \pm 0.21 \#$ & $0.63 \pm 0.15$ \\
\hline Total n-3 PUFA & $2.6 \pm 0.4$ & $2.7 \pm 0.6$ & $2.8 \pm 0.4$ & $2.5 \pm 0.8$ \\
\hline Total n-3 LCP & $1.5 \pm 0.6$ & $1.2 \pm 0.3$ & $1.8 \pm 0.3$ & $0.9 \pm 0.2$ \\
\hline
\end{tabular}

Student's $t$-test and Kruskall-Wallis test: * $p<0.05 ; \# p<0.05$. 


\section{References}

1. Masson L, Mella MA. Materias grasas de consumo habitual y potencial en Chile. Facultad de Ciencias químicas, Farmacéuticas. Santiago: Universidad de Chile; 1985

2. Schmidt-Hebbel H, Penneccliotti Y, Masson L, Mella MA. Tabla de composición química de alimantos chilenos. $8^{\mathrm{a}}$ edición. Facultad de Ciencias químicas, Farmacéuticas. Santiago: Universidad de Chile; 1990

3. Neville MC, Keller RP, Seacat J, et al. Studies on human lactation. Within-feed and between-breast variation in selected components of human milk. Am J Clin Nutr 1984; 40: 635-42

4. Allen JC, Keller RP, Archer P, Neville MC. Studies in human lactation: milk composition and daily secretion rates of macronutrients in the first year of lactation. Am J Clin Nutr 1991; 54: 69-80

5. Lepage G, Roy CC. Direct transesterification of all classes of lipids in a one-step reaction. J Lipid Res 1986; 27: 114-20

6. Bligh EG, Dyer WJ. A rapid method of total lipid extraction and purification. Can J Biochem Physiol 1959; 37: 911-7

7. Salem N, Wegher B, Mena P, Uauy R. Arachidonic and docosahexaenoic acids are biosynthesized from the 18-carbon precursors in human infants. Proc Natl Acad Sci USA 1996; 93: 4954

8. Scopesi F, Ciangherotti S, Lantieri PB, Risso D, Bertini I, Campone F, Pedroti A, Serra G, Bonacci W. Maternal dietary
PUFAs intake and human content relationship during the first month of lactation. Clin Nutrition 2001; 20: 393-7

9. Pugo-Gunsam P, Guesnet P, Subratty AH, Rajcoomar DA, Maurage C, Couet C. Fatty acid composition of white adipose tissue and breast milk of Mauritanian and French mothers and erythrocyte phospholipids of their full-term breast-fed infants. $\mathrm{Br}$ J Nutr 1999; 82: 263-71

10. Xiang M, Lei S, Li T, Zetterström R. Composition of long chain polyunsaturated fatty acids in human milk and growth of young infants in rural areas of northern China. Acta Paediatr 1999; 88 : 126-31

11. Valenzuela A, Uauy R. Consumption pattern of dietary fats in Chile: n-6 and n-3 fatty acids. Int J Food Scien Nutr 1999; 50: 127-33

$M_{\text {Milad }}{ }^{l}, P$ Mena $^{1,2}, S$ Nieto $^{2}, R$ Uauy $^{2,3}$, Division of Neonatology ${ }^{l}$, Sotero del Rio Hospital, Santiago; Institute of Nutrition and Food Technology ${ }^{2}$, INTA, University of Chile, Santiago, Chile; (3) Retina Foundation of the Southwest ${ }^{3}$, Dallas, Texas, USA. Correspondence to: M Milad, Lo Recabarren 6422 Vitacura, Santiago, Chile (Tel. +56 (2) 2427205, fax. +56 (2) 2419196, e-mail. mmilad@manquehue.net) or P Mena, Sagrados Corazones 3697. Providencia, Santiago, Chile (e-mail.pmena@uec.inta.uchile.cl)

Received Nov. 19, 2003; accepted Nov. 30, 2003

\section{Severe Acute Respiratory Syndrome in children: a clue to better understanding the disease and advancing towards solutions}

Sir,

Severe Acute Respiratory Syndrome (SARS) is a disease caused by a new coronavirus that has generated worldwide concern. In the adult population, respiratory distress is the main cause of mortality. In our view, there is an open question: what is the underlying cause of evolution to respiratory distress: a viral direct cytopathic damage, an immune-mediated damage in response to the viral infection or both? Evidence of immune implication in SARS pathogenesis comes from autopsies (1), which show a pronounced increase in macrophages in the alveoli and the interstitium of the lung and haemophagocytosis (thought to be in relation with an incorrect regulation of $\mathrm{T}$ lymphocytes and cytokines). Therefore, pro-inflammatory cytokines released by stimulated macrophages in the alveoli could have a prominent role in SARS pathogenesis. Additionally, reports coming from China testing levels of cytokines on serum and blood samples show that most pro-inflammatory cytokines are elevated during the early phase of SARS (2). Pre-existing comorbidity, particularly diabetes, is related to an increased mortality, but immuno- supressive states such as HIV infection are not. It is supposed that the virus comes from an animal host. On this basis, it does not seem to be hazardous to suppose an incorrect or exacerbated immune response against this non-common virus. At this point, the first reports about SARS in paediatric patients reveal a surprising conclusion: to date, there have been no reported case fatalities in children with this disease, in contrast with the 774 deaths registered in adults. The severity is much milder and the clinical progression much less aggressive in young children, while adolescents (12y or older) resemble adults in their clinical features. In general, younger children do not require oxygen supplementation or immunosupressors and do not develop radiographic findings consistent with acute respiratory distress syndrome (3-6). The benign course of SARS in children presents several implications. (1) It discards an important direct viral cytopathic component for respiratory distress: children would be the most affected patients given the immaturity of their immune system. (2) On the other hand, severity of the disease is worst in patients with an adult immune system. This implies that 